OPEN ACCESS

Edited by:

Carlos E. Plancha,

University of Lisbon, Portugal

Reviewed by:

Juan Manuel Teijeiro,

CONICET Rosario, Argentina

Matteo Avella,

University of Tulsa, United States

${ }^{*}$ Correspondence:

Satish Kumar Gupta skgupta@nii.ac.in; skgupta.nii53@gmail.com

Specialty section:

This article was submitted to Signaling,

a section of the journa Frontiers in Cell and Developmental

Biology

Received: 21 October 2020

Accepted: 21 January 2021

Published: 11 February 2021

Citation:

Gupta SK (2021) Human Zona

Pellucida Glycoproteins: Binding

Characteristics With Human

Spermatozoa and Induction of Acrosome Reaction.

Front. Cell Dev. Biol. 9:619868. doi: 10.3389/fcell.2021.619868

\section{Human Zona Pellucida Glycoproteins: Binding Characteristics With Human Spermatozoa and Induction of Acrosome Reaction}

\author{
Satish Kumar Gupta* \\ Reproductive Cell Biology Lab, National Institute of Immunology, New Delhi, India
}

Human zona pellucida (ZP) matrix is composed of four glycoproteins designated as ZP glycoprotein -1 (ZP1), -2 (ZP2), -3 (ZP3), and -4 (ZP4). Mutations in the genes encoding human ZP glycoproteins are one of the causative factors leading to abnormal ZP matrix and infertility in women. Relevance of the human ZP glycoproteins in 'sperm-oocyte' binding has been delineated by using either transgenic animal models expressing human zona proteins or purified native/recombinant human zona proteins. Studies based on the purified native/recombinant human zona proteins revealed that ZP1, ZP3, and ZP4 primarily bind to the capacitated acrosome-intact human spermatozoa whereas ZP2 binds to acrosome-reacted spermatozoa. On the contrary, human spermatozoa binds to the eggs obtained from transgenic mouse lines expressing human ZP2 but not to those expressing human ZP1, ZP3, and ZP4 suggesting that ZP2 has an important role in human 'sperm-oocyte' binding. Further studies using transgenic mouse lines showed that the N-terminus of human ZP2 mediate the taxon-specific human sperm-oocyte binding. Both glycans and protein-protein interactions have a role in human gamete interaction. Further studies have revealed that the purified native/recombinant human ZP1, ZP3, and ZP4 are competent to induce acrosome reaction. Human sperm binds to the mouse transgenic eggs expressing human ZP1-4 instead of mouse ZP1-3 proteins, penetrated the ZP matrix and accumulated in the perivitelline space, which were acrosome-reacted suggesting that human ZP2 in transgenic mouse model also induce acrosome reaction. In humans $N$-linked glycosylation of zona proteins have been shown to play an important role in induction of the acrosome reaction. Hence in humans, based on studies using transgenic mouse model as well as purified native/recombinant zona proteins, it is likely that more than one zona protein is involved in the 'sperm-oocyte' binding and induction of the acrosome reaction.

Keywords: human zona pellucida glycoproteins, mutations in genes encoding human zona glycoproteins, zona proteins binding to sperm, ZP glycoproteins-mediated acrosome reaction, fertilization 


\section{BACKGROUND}

Zona pellucida (ZP), an extracellular glycoproteinaceous coat surrounding human oocyte is composed of four glycoproteins designated as zona pellucida glycoprotein -1 (ZP1), -2 (ZP2), -3 (ZP3), and -4 (ZP4). ZP glycoproteins play a critical role in 'oogenesis', taxon-specific binding of the spermatozoa to the oocyte and induction of acrosome reaction (AR) in the spermatozoa bound to the ZP thereby facilitating accomplishment of fertilization. In essence, the ZP matrix serves as a 'gate-keeper' to regulate sperm binding (Hartmann et al., 1972). The human sperm binds to the human egg and do not bind with the eggs from other sub-hominoid primates such as baboon, rhesus monkey, and squirrel monkey as well as nonprimate eutherian species (Bedford, 1977). The only exception to which human sperm binds is the oocytes of Gorilla gorilla and Hylobates lar (gibbon). Whereas, mouse sperm can bind to eggs from a taxonomically diverse group of mammals, including humans (Bedford, 1977). ZP glycoproteins also have a role in the prevention of polyspermy and ZP matrix protects the growing embryo till implantation.

In all eutherian mammals studied so far, ZP matrix has both ZP2 and ZP3. However, ZP1 and ZP4, which are encoded by paralogous genes probably formed by duplication of a common ancestral gene may or may not be present in all eutherian mammals (Goudet et al., 2008). For example, the ortholog of the human ZP4 gene is present in the mouse genome as a pseudogene due to microdeletion of nucleotides leading to frame shift and appearance of a premature stop codon. Thus, functional ZP4 protein is not present in mouse ZP matrix (Lefievre et al., 2004; Goudet et al., 2008). Similarly, ZP1 has been identified as a pseudogene in the dog and bovine genome (Goudet et al., 2008). High resolution Scanning Electron Microscopy (SEM) studies with human oocytes revealed that $\mathrm{ZP}$ appears as a delicate meshwork of thin interconnected filaments (Familiari et al., 1992, 2006). The filaments are 0.1$0.4 \mu \mathrm{m}$ in length and $10-14 \mathrm{~nm}$ in thickness as observed by Transmission Electron Microscopy (Familiari et al., 1992). In mouse $\mathrm{ZP}$, the filaments are composed of ZP2 and ZP3 heterodimers, which are cross-linked by ZP1 homodimers (Greve and Wassarman, 1985; Green, 1997). The precise arrangement of ZP filaments in the human ZP matrix has not been deciphered. However, supramolecular structure based on the structural information of ZP glycoproteins has been proposed for human ZP (Bokhove and Jovine, 2018). It comprises of filaments with a structural repeat of $\sim 14 \mathrm{~nm}$ formed by alteration of ZP3 and either ZP2 or ZP4. ZP1 will be occasionally incorporated instead of ZP2/ZP4 and stabilizes the ZP by intermolecular cross-links between filaments (Bokhove and Jovine, 2018). Recently, it has been shown that ZP filaments are indeed cross-linked by ZP1 homodimers leading to the formation of a stable matrix (Nishimura et al., 2019). Meshwork of filaments leads to formation of the pores that appear larger at the outer surface of the zona than the inner surface. Ultrastructural cytochemical findings further suggested that the porous region of the human $\mathrm{ZP}$ is limited to $\sim 25 \%$ of the external region of the human $\mathrm{ZP}$, while the compact region constitutes $\sim 75 \%$ of the total ZP. The amorphous spongy outer surface of zona with larger pores may facilitate sperm penetrability as human ZP with a more compact and smoother outer surface has been shown to be less penetrable (Familiari et al., 1988, 1992). On the contrary, no correlation was observed between the ZP morphology and success of in vitro fertilization (Magerkurth et al., 1999).

In this 'review', characteristics of the respective human ZP glycoproteins will be briefly described. The role of mutations in the genes encoding human ZP glycoproteins leading to morphologically abnormal oocytes and infertility will be discussed. The relevance of human ZP glycoproteins for binding with human spermatozoa and their ability to induce AR as observed by using either transgenic animal models or purified native/recombinant proteins will be described.

\section{EXPRESSION PROFILE OF THE ZP GLYCOPROTEINS IN HUMAN OOCYTES}

Expression of human ZP3 has been observed in the oocytes of fetal ovary (Törmälä et al., 2008). By immunohistochemistry, expression of human ZP1, ZP2, and ZP3 has been observed in oocytes as well as granulosa cells of the primordial follicles (Gook et al., 2008). Expression of ZP4 has been described in the zona of mature oocytes (Lefievre et al., 2004). Contrary to these observations, employing highly specific mouse monoclonal antibodies raised against recombinant human $\mathrm{ZP2}, \mathrm{ZP} 3$, and ZP4 and synthetic peptide (219-258 aa residues) corresponding to human ZP1, expression of human ZP1, ZP2, and ZP3 is observed in oocytes of growing and antral follicles (Bukovsky et al., 2008; Ganguly et al., 2010b). Expression of ZP4 is observed in oocytes of primordial, growing and antral follicles (Bukovsky et al., 2008). Expression of ZP1 and ZP2 though not observed in oocytes of primordial follicles but it is observed in oocytes of primordial follicles undergoing atresia (Bukovsky et al., 2008; Ganguly et al., 2010b). Employing human cumulus oocyte complexes, it has been shown that the expression of $Z P 1, Z P 2$, and $Z P 4$ at the transcript level is higher in immature (Metaphase 1, M1/Germinal Vesicle, GV) oocytes as compared to mature (Metaphase II, MII) oocytes. This coincides with the smaller inner layer-ZP area and thickness in the mature as compared to immature oocytes (Canosa et al., 2017). These observations suggest that the nascent ZP glycoproteins are incorporated into the inner surface of the ZP matrix. Hence, thickening of the ZP matrix takes place from inside to the outside.

\section{GENOMIC ORGANIZATION OF HUMAN ZP GLYCOPROTEINS AND FUNCTIONAL SIGNIFICANCE OF THE COMMON STRUCTURAL MOTIFS}

The human genome contains four $Z P$ genes: $Z P 1, Z P 2, Z P 3$, and $Z P 4$, which are located on chromosomes $10,16,7$, and 1 , respectively (Hughes and Barrat, 1999). 


\section{Human ZP1}

The human $Z P 1$ gene has 12 exons and encodes a polypeptide of 638 amino acid (aa) (Lefievre et al., 2004). Expression of ZP1 mRNA is low in the fetal as well as adult ovaries (Törmälä et al., 2008). Human ZP1 has a 25 aa long signal peptide, 41 aa long 'trefoil domain,' signature 'ZP domain' from 279 to 548 aa and consensus furin cleavage site (CFCS), RQRR, from 552 to 555 aa. 'ZP domain' of human ZP1 consists of two subdomains, ZP-N and ZP-C. From human ZP1-N subdomain, two 'aggregation-prone' peptides have been predicted that may be crucial for ZP protein polymerization as these peptides self-assemble into amyloid-like fibrils (Louros et al., 2013). In humans, filaments are cross-linked by ZP1-N subdomain of $\mathrm{ZP} 1$ leading to the formation of stable $\mathrm{ZP}$ matrix, which can be modulated by ZP1 fucosylation and zinc sparks (Nishimura et al., 2019). At aa level, human ZP1 has 47\% identity with human ZP4 suggesting that these two proteins may have evolved from a common ancestral gene either by gene duplication or exon swapping.

\section{Human ZP2}

The human $Z P 2$ gene has 19 exons and encodes a 745 aa long polypeptide. ZP2 has 38 aa long signal peptide, 'ZP domain' from 372-637 aa and CFCS, RHRR from 639 to 642 aa.

\section{Human ZP3}

The human $Z P 3$ gene has 8 exons and encodes a 424 aa long polypeptide. It has a 22 aa long signal peptide, 'ZP domain' corresponding to aa residues 45-303 and CFCS, RNRR from 349 to 352 aa. In humans, second polymorphic locus for human $Z P 3$ encoding a truncated protein corresponding to 372 aa residues in addition to full-length ZP3 has also been reported (van Duin et al., 1992). In addition, a bipartite RNA transcript encoded by $P O M-Z P 3$ gene that is derived from a gene homologous to rat POM121 (encode a nuclear pore membrane protein) and 4 C-terminal exons of human $Z P 3$ has also been reported in humans (Kipersztok et al., 1995).

\section{Human ZP4}

The human ZP4 gene has 13 exons and encodes a 540 aa long polypeptide with 18 aa long signal peptide, 'trefoildomain' corresponding to 141-183 aa residues, 'ZP domain' corresponding to 188-460 aa residues and CFCS, SRRR, from 463 to 465 aa residues. Self-assembly of peptides corresponding to a common interface of human ZP2, ZP3, and ZP4 into fibrils with distinct amyloid-like features have been reported. It suggests that 'ZP domain' plays an important role in polymerization and self-assembly of ZP glycolproteins (Louros et al., 2016).

The deduced amino acid (aa) sequence of the four human ZP glycoproteins revealed some common structural elements, which plays an important role in their secretion, incorporation in the ZP matrix, structure and function. All four human ZP glycproteins have N-terminal hydrophobic signal peptide that targets them to the secretory pathway through co-translational import into the endoplasmic reticulum and which ultimately gets cleaved from the mature proteins by signal peptidase present in the oocytes. Human ZP1 and ZP4 have 'trefoil domain', which is absent in ZP2 and ZP3. 'Trefoil domain' has a characteristic pattern of 6 conserved cysteine in a trefoillike arrangement and is found in a family of small peptides called the Trefoil family (Thim, 1989). The structural and/or functional significance of its presence in human ZP1 and ZP4 is not clear. All four human ZP glycoproteins share a motif designated as the 'ZP domain', which consists of approximately 260 aa including 8 conserved cysteine residues and is predicted to have high $\beta$-strand content with additional conservation of hydrophobicity, polarity, and turn-forming tendency (Bork and Sander, 1992; Jovine et al., 2005). It has a bipartite structure with ZP-N and ZP-C subdomains separated by a protease-sensitive region. 'ZP domain' plays an important role in the polymerization of human zona proteins into filaments (Jovine et al., 2002). Immediately after 'ZP domain' all four human ZP glycoproteins have CFCS. Proteolytic cleavage at CFCS by proprotein convertase enzyme is critical for the secretion and assembly of human ZP3 in ZP matrix (Kiefer and Saling, 2002). The importance of CFCS in the secretion and assembly of other human zona proteins is still awaited. It is also not clear if the cleavage takes place either in the Golgi or at the egg plasma membrane. Downstream of CFCS, hydrophobic transmembrane-like domain (TMD) and short cytoplasmic tail is present in all the four human ZP glycoproteins. The functional significance of TMD and cytoplasmic tail for human ZP glycoproteins is not known. However, cytoplasmic tails of mouse ZP2 and ZP3 prevent their premature intracellular interaction and thus plays an important role in the incorporation of $\mathrm{ZP} 2$ and $\mathrm{ZP} 3$ into the $\mathrm{ZP}$ matrix (Jimenez-Movilla and Dean, 2011).

\section{BIOCHEMICAL CHARACTERISTICS OF HUMAN ZP GLYCOPROTEINS}

Iodination and subsequent two-dimensional SDS-PAGE analysis of the heat solubilized isolated zona pellucida (SIZP) from human eggs showed three acidic proteins with molecular weights ranging from 64 to $78 \mathrm{kDa}$ (ZP2), 57 to $73 \mathrm{kDa}$ (ZP3), and 90 to $110 \mathrm{kDa}$ (ZP4; previously classified as ZP1) (Shabanowitz and O'Rand, 1988). Using antibodies generated against synthetic peptides, ZP2 has been characterized as 90$110 \mathrm{kDa}$ and ZP3 as 53-60 kDa glycoproteins (Bauskin et al., 1999). Using highly specific mouse monoclonal antibodies raised against recombinant human $\mathrm{ZP} 2, \mathrm{ZP} 3$, and $\mathrm{ZP} 4$, these proteins have been purified from the human eggs by immunoaffinity column chromatography. The purified native human $\mathrm{ZP2}$, $\mathrm{ZP} 3$, and $\mathrm{ZP} 4$ (also contaminated with $\mathrm{ZP} 1$ ) revealed $\sim 120$, $\sim 58$, and $\sim 65 \mathrm{kDa}$ bands respectively in denaturing SDSPAGE (Chiu et al., 2008b). Based on deduced aa sequence, the calculated molecular weight of human ZP1, ZP2, ZP3, and $\mathrm{ZP} 4$ is $57,82,47$, and $59 \mathrm{kDa}$ respectively. The higher molecular weight of the purified native human ZP2, ZP3, and ZP4 from the human eggs as compared to the calculated molecular weight of the respective protein may be due to 
glycosylation. Analyses of human ZP by 2-D SDS-PAGE and Western blots revealed that ZP2, ZP3, and ZP4 showed multiple isoforms, which may be due to varying extend of glycosylation (Bercegeay et al., 1995; Gupta et al., 1998). Using lectins, high concentration of $\mathrm{D}$-mannose residues have been reported in the human ZP (Maymon et al., 1994). Further characterization using lectins and antibodies revealed the presence of sialyl-Lewis ${ }^{a}$, sialyl-Lewis ${ }^{x}$, Neu5Ac $\alpha 2-3 \mathrm{Gal} \beta 1,4 \mathrm{Glc}$ NAc, Gal $\beta 1,3$ GalNAc-Ser/Thr, Neu5Ac $\alpha 2,6 \mathrm{Gal} / \mathrm{GalNAc}$, fucosylated oligosaccharides, $N$-acetylgalactosamine residues, galactose residues, and $N$-acetylglucosamine residues in the ZP matrix of human oocytes (Jiménez-Movilla et al., 2004). Further analyses of purified human ZP2, ZP3, and ZP4 subsequent to either $N$-glycosidase-F treatment (removal of $N$-linked oligosaccharides) or alkaline reduction (removal of $O$-linked oligosaccharides) suggested that $N$-linked glycosylation occupies $\sim 37 \%, \sim 27 \%$, and $\sim 18 \%$ of the molecular mass of ZP2, ZP3, and ZP4, respectively (Chiu et al., 2008b). Human ZP2 has $\sim 8 \%$ and ZP3 has $\sim 9 \%$ O-linked glycosylation. Alkaline reduction of purified human $\mathrm{ZP} 4$ did not lead to any significant reduction in its electrophoretic mobility in denaturing SDSPAGE suggesting that it either has no $O$-linked glycosylation or minimally O-linked glycosylated (Chiu et al., 2008b). These observations clearly show that human $\mathrm{ZP}$ glycoproteins have more $N$-linked as compared to $O$-linked glycosylation. SialylLewis $^{x}$ sequence [NeuAC $\alpha 2-3 \mathrm{Gal} \beta 1-4(\mathrm{Fuc} \alpha 1-3)$ GlcNAc] is the most abundant terminal sequence on the $N$ - and $O$-glycans as revealed by the mass spectrometric analysis of the human ZP (Pang et al., 2011).

\section{MUTATIONS IN GENES ENCODING HUMAN ZONA PROTEINS: PROBABLE CAUSATIVE FACTOR FOR INFERTILITY IN WOMEN}

Analysis of $Z P 1, Z P 2, Z P 3$, and $Z P 4$ genes in women whose eggs fail to fertilize using in vitro fertilization (IVF) as compared to those with successful fertilization following IVF as well as women with proven fertility showed 1.5-fold increase in sequence variation in $Z P 1$ and $Z P 3$ genes (Männikkö et al., 2005). An additional study in infertile women revealed sequence variations in genes encoding $Z P 2$ and $Z P 3$ (Pökkylä et al., 2011). Analysis of the nucleotide sequence of $Z P 1$ gene from six members of the family (five sisters and one brother; four sisters diagnosed with primary infertility; two out of four sisters had eggs which were not surrounded with ZP matrix, other two sisters had no eggs) revealed homozygous frameshift mutations inherited in an autosomal recessive mode, which led to premature stop codon and resulted in a truncated ZP1 (404 aa residues), which was postulated to sequester ZP3 in the cytoplasm and prevented the formation of ZP matrix (Huang et al., 2014). Two mutations in the gene encoding ZP1 [one missense variant c.247T > C (p.W83R) and one nonsense variant c.1413G > A (p.W471X)] have also been reported from infertile women who had oocytes with morphological defects (Yang et al., 2017). The nonsense variant c.1413G > A is located in the ' $\mathrm{ZP}$ domain' and leads to premature stop codon resulting in truncation of the ZP1 protein from 638 aa to 471 aa (Yang et al., 2017). In the same study, another 33-year-old woman showed ZP2 variant c.1696T > C in exon 16 leading to change of cysteine with arginine at position 566 (p.C566R). In another 28-year-old woman, variant c.1599G $>\mathrm{T}$ in exon 15 of $Z P 2$ that led to the replacement of arginine to serine (p.R533S) has also been reported (Yang et al., 2017). Two novel heterozygous mutations in $Z P 2$ (c.2092C > T; arginine at $698^{\text {th }}$ position replaced by a stop codon) and ZP3 (c.1045_1046 insT; arginine at $349^{\text {th }}$ position replaced by $\mathrm{L}$ amino acid followed by a stop codon) from a woman and her family members with abnormal ZP have also been reported (Liu et al., 2017). Further studies in mouse model using CRISPR/Cas9 gene editing technology revealed that oocytes obtained from mice with either of the heterozygous mutations showed thinner ZP as compared to the oocytes obtained from wild mice. Interestingly, oocytes from female mice with both mutations showed even thinner ZP as compared to the ZP of oocytes with single mutation or absence of $\mathrm{ZP}$ suggesting that these mutations have dosage effect with respect to the formation of $\mathrm{ZP}$ (Liu et al., 2017). Both the mutant proteins failed to anchor on the oocyte membrane. A paternally transmitted heterozygous missense mutation of c.400 G > A (p.A134T) in ZP3 in women with empty follicle syndrome has also been reported. Immunofluorescence and histological analysis revealed degenerated oocytes and some of which were devoid of ZP matrix (Chen et al., 2017). In another recent study, seven patients belonging to six independent families with abnormal oocytes or those suffered from empty follicle syndrome revealed three homozygous mutations in ZP1 [c.1708G > A (p.V570M), c.1228C > T (p.R410W), c.507del (p.H170Iefs*52)], two mutations in a compound heterozygous state in ZP1 [c.1430 + $1 \mathrm{G}>\mathrm{T}$ (p.C478X), c.1775-8T > C (p.D592Gfs*29)], a homozygous mutation in ZP2 [c.1115G > C (p.C372S)], and a heterozygous mutation in $Z P 3[\mathrm{c} .763 \mathrm{C}>\mathrm{G}$ (p.R255G)]. Interestingly, expression studies of human ZP1, $\mathrm{ZP}$, and ZP3 with these mutations in $\mathrm{CHO}$ cells showed defects in their expression, secretion, and interaction suggesting that these mutations are responsible for the abnormal oocyte phenotype observed in these patients (Zhou et al., 2019). Two homozygous mutations in ZP2 [c.1695-2A > G and c.1691_1694dup (p.C566Wfs*5)] have also been reported in women with a thin $\mathrm{ZP}$ and defective sperm binding to the oocyte from two unrelated consanguineous families (Dai et al., 2019). Expression studies in CHO cells led to truncated ZP2 protein. Whole-exome sequencing of $Z P 1$ in two infertile sisters from a family with empty follicle syndrome revealed compound heterozygous mutations. Co-immunoprecipitation studies and homology modeling analysis showed that both mutated ZP1 disrupt the formation of oocyte ZP by interrupting the interaction among ZP1, ZP2, and ZP3 (Sun et al., 2019). These studies suggest that deleterious mutations in the genes encoding human ZP glycoproteins are one of the causative factors for female infertility due to defective $\mathrm{ZP}$ and leading to failure of fertilization. 


\section{ROLE OF HUMAN ZP GLYCOPROTEINS IN BINDING TO THE SPERMATOZOA AND INDUCTION OF ACROSOME REACTION}

Human ZP matrix is composed of four glycoproteins whereas mouse ZP matrix is composed of three glycoproteins. It is pertinent to know, if the role of respective human $\mathrm{ZP}$ glycoproteins in sperm-oocyte binding and induction of AR is same as deciphered in mouse model or additional proteins are involved during these steps to accomplish fertilization. In mouse model, the function of individual ZP glycoproteins during fertilization has been elucidated with 'loss-of-function' by targeted mutagenesis of individual ZP genes in embryonic stem cells to generate null mutant mice defective for one of the zona proteins. Further, transgenic mouse lines expressing human ZP proteins have been developed to study the binding of human sperm to transgenic mouse eggs that is 'gain-of-function' (Avella et al., 2013). In addition to transgenic animal models, purified native/recombinant human ZP proteins have also been used to delineate their biological functions during sperm-egg binding and induction of AR (Gupta et al., 2012; Gupta, 2018). The salient findings with respect to the role of various $\mathrm{ZP}$ glycoproteins during sperm-egg binding and induction of $A R$ will be described below using both these approaches.

\section{Human ZP1}

Studies Using Transgenic Mouse Model Revealed No Role of ZP1 in Sperm-Egg Binding

To delineate the role of ZP1 during fertilization, $Z P 1$-null mouse lines have been developed by targeted mutagenesis of $Z P 1$ in embryonic stem cells (Rankin et al., 1999). In ZP1 null mice, the $\mathrm{ZP}$ is composed of only mouse $\mathrm{ZP} 2$ and $\mathrm{ZP} 3$ and the matrix is more loosely organized than zonae around normal oocytes. These mice have perturbed folliculogenesis and after mating with males, fewer two-cell embryos are recovered from ZP1 null mice. Hence, mouse ZP1 is not essential for sperm binding or fertilization but it is required for structural integrity of the ZP matrix to minimize precocious hatching and reduced fecundity (Rankin et al., 1999). Subsequently, to delineate the role of human ZP1 in sperm-egg binding, transgenic mouse expressing human $Z P 1$ was crossed with ZP1-null background mouse to produce transgenic mouse lines with zonae expressing human ZP1, mouse ZP2, and mouse ZP3 (Baibakov et al., 2012). The eggs obtained from these transgenic mice failed to bind human sperm suggesting that ZP1 may not be involved in human sperm-egg binding (Baibakov et al., 2012).

\section{Recombinant Human ZP1 Binds to the Capacitated Human Spermatozoa and Induces AR}

As of today, there is no report of purification of the human ZP1 from human eggs. However, human ZP1 (26-551 aa residues) without signal peptide sequence and till the CFCS has been expressed in E. coli as well as in insect cells (Ganguly et al., 2010b). Both baculovirus- and E. coli-expressed recombinant human ZP1 binds to the capacitated acrosome-intact human sperm (Table 1).
In calcium ionophore-induced acrosome-reacted human sperm, ZP1 binding to the acrosomal cap is lost and its binding is restricted to the equatorial region only. In an additional study, the importance of ' $\mathrm{ZP}$ domain' of ZP1 for binding to the capacitated spermatozoa has also been shown (Ganguly et al., 2010a; Table 1). Baculovirus-expressed recombinant human ZP1 (273-551 aa residues) encompassing 'ZP domain' of ZP1, showed binding profile with capacitated acrosome-intact and acrosome-reacted human sperm similar to that observed with recombinant human ZP1 (26-551 aa residues). Interestingly, incubation of the capacitated human sperm with baculovirusexpressed recombinant human ZP1 (26-551 aa residues) as well as recombinant protein corresponding to 'ZP domain' of ZP1 (273-551 aa residues) led to a dose dependent significant increase in the AR (Ganguly et al., 2010a,b; Figure 1). Approximately 30\% sperm undergo AR in presence of recombinant human ZP1 (26551 aa residues; $10 \mu \mathrm{g} / \mathrm{ml}$ ) and $\sim 40 \%$ in presence of $\mathrm{ZP}$ domain of ZP1 ( $5 \mu \mathrm{g} / \mathrm{ml})$ as compared to $\sim 8 \%$ either spontaneous AR or in presence of Fetuin (Ganguly et al., 2010a,b). However, E. coliexpressed recombinant human ZP1 (26-551 aa residues), though binds to the capacitated spermatozoa but failed to induce any significant increase in the AR. These observations suggest that glycosylation of human ZP1 is important for induction of the AR. The studies using recombinant human ZP1 suggests that it has a role in human sperm-egg binding, which are contrary to the observations from transgenic mouse model (Table 2).

\section{Human ZP2}

\section{Transgenic Mice Studies Revealed the Role of ZP2 in Sperm-Egg Binding}

To delineate the role of ZP2 during fertilization, $Z P 2$ knockout transgenic mouse lines have been developed. In $Z P 2$ null mice, a thin ZP matrix in early follicles with mouse ZP1 and ZP3 synthesis has been observed that could not be sustained in pre-ovulatory follicles (Rankin et al., 2001). The abnormal ZP matrix does not affect initial folliculogenesis, but there is a significant reduction in the number of antral stage follicles. No 2-cell embryos are recovered after mating ZP2 null females with normal male mice, suggesting that mouse ZP2 has a role during fertilization and early embryo development (Rankin et al., 2001). Further, transgenic mouse lines expressing mouse ZP1, mouse ZP3 and human ZP4 but not mouse ZP2 have also been developed with normal appearing ZP matrix (Avella et al., 2014). The eggs obtained from these transgenic mice lacking expression of mouse ZP2 failed to bind mouse sperm suggesting that mouse ZP2 is required for sperm-egg binding and fertility (Avella et al., 2014). In mice, post-fertilization ZP2 undergoes proteolytic cleavage by oocyte-specific ovastacin - a metalloendoprotease leading to changes in the supramolecular structure of the ZP matrix and thereby prevent polyspermy (Burkart et al., 2012). If the ovastacin cleavage site $\left({ }^{166} \mathrm{LA} \mathrm{DE}^{169}\right)$ was mutated in transgenic mice or ovastacin was genetically ablated, ZP2 does not undergo cleavage and sperm continued to bind early embryo (Gahlay et al., 2010; Burkart et al., 2012). Additional experiments are needed to show whether ZP2 also has a role in avoidance of polyspermy during fertilization in humans. 
TABLE 1 | Binding profile of human zona pellucida glycoproteins to the capacitated acrosome-intact and acrosome-reacted human sperm.

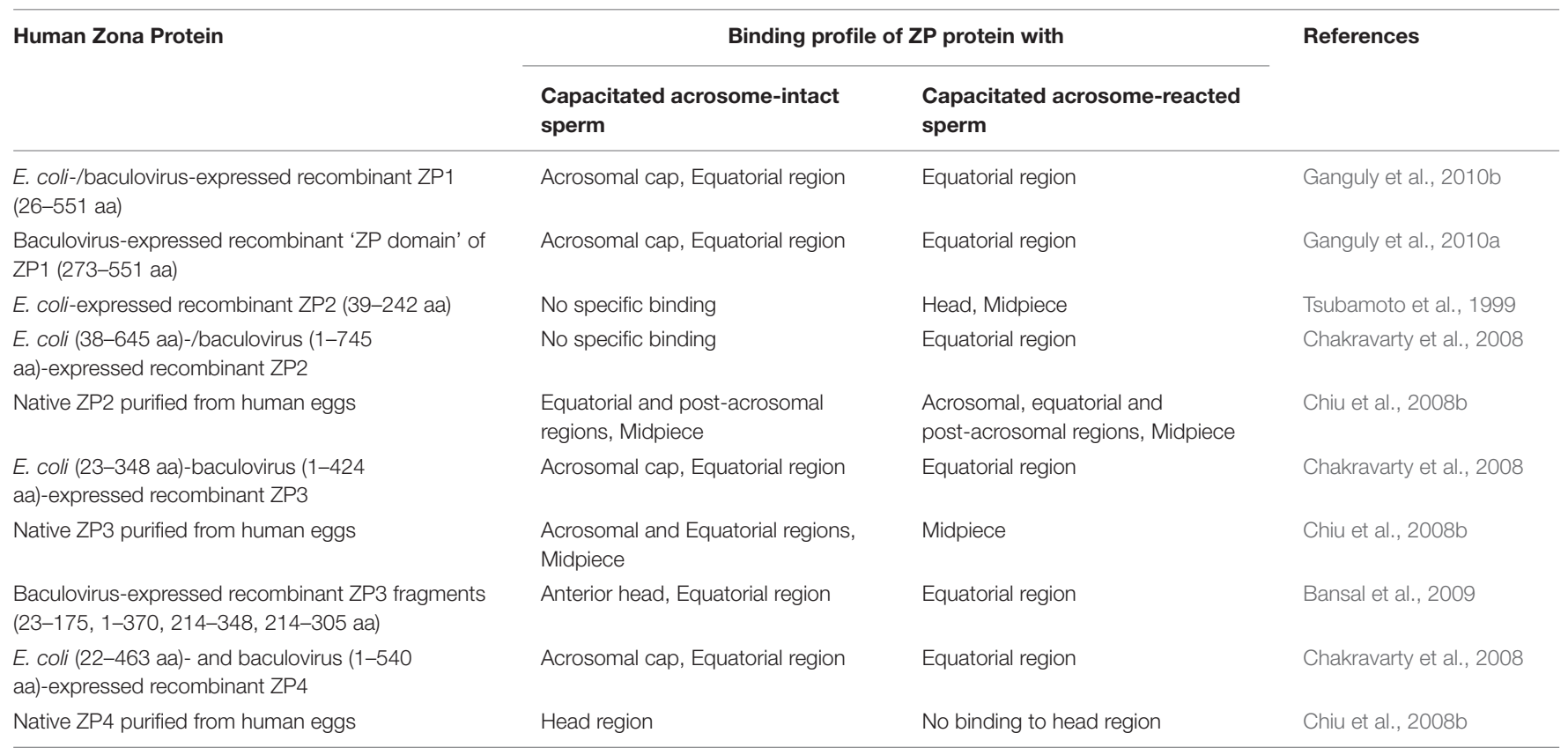

Subsequently, transgenic mouse lines wherein mouse ZP2 and/or ZP3 were replaced with human homologs have been developed (Rankin et al., 2003). The eggs obtained from transgenic mice expressing human ZP2, mouse ZP1, and mouse ZP3 failed to bind human sperm (Rankin et al., 2003). However, eggs from these transgenic mice showed in vitro binding of mouse sperm leading to successful fertilization and formation of twocell embryo. After fertilization, human ZP2 failed to be cleaved by ovastacin and mouse sperm showed continued binding with early rescued embryos (Rankin et al., 2003). Further, four transgenic mouse lines expressing human ZP1, ZP2, ZP3, and ZP4 were crossed to establish transgenic mouse line expressing human ZP1-4 in place of mouse ZP1-3 (Baibakov et al., 2012). In vitro sperm-egg binding assay revealed that human sperm bind to the transgenic zonae expressing human $\mathrm{ZP} 2$, mouse $\mathrm{ZP} 1$, and mouse ZP3 as well as transgenic zonae expressing human ZP14 proteins in place of mouse ZP1-3 (Baibakov et al., 2012; Avella et al., 2014; Figure 2). The failure to observe human sperm binding to the transgenic zonae expressing human $\mathrm{ZP} 2$, mouse ZP1 and mouse ZP3 in the previous study (Rankin et al., 2003) was due to the insufficient time allowed for capacitation of human sperm (Baibakov et al., 2012; Avella et al., 2014). In case of transgenic eggs expressing human ZP1-4, human sperm not only bind to the eggs but also penetrated ZP matrix and accumulated in the perivitelline space (Avella et al., 2014). The sperm accumulated in perivitelline space are acrosome-reacted. Using DNA recombinant technologies and pronuclear injection, transgenic mouse lines expressing human exons encoding human ZP2 (22-164 aa residues) and mouse exons encoding mouse ZP2 (18-156 aa residues) either as hu/moZP2 or mo/huZP2 configuration have been developed. In addition, zonae from the above transgenic mouse lines also expressed mouse ZP1 and $\mathrm{ZP} 3$. The $\mathrm{ZP}$ of the chimeric hu/moZP2 eggs reacted with human ZP2 N-terminus and mouse ZP2 C-terminus but not mouse ZP2 N-terminus recognizing monoclonal antibodies. The ZP surrounding the chimeric mo/huZP2 eggs reacted with antibodies to the $\mathrm{N}$-terminus but not the $\mathrm{C}$-terminus of mouse ZP2. Human sperm bind to the chimeric zonae expressing hu/moZP2 but not to those expressing mo/huZP2 chimeric protein thereby suggesting that the N-terminus of ZP2 mediate the taxon-specificity of human sperm binding to the $\mathrm{ZP}$ (Avella et al., 2014).

\section{Human ZP2 Protein/Fragment Binds to Either Capacitated or Acrosome-Reacted Human Sperm}

Contradictory observations about the ability of native and/or recombinant human $\mathrm{ZP} 2$ for binding to the capacitated human spermatozoa have been reported. It has been demonstrated that agarose beads coated with recombinant human ZP2 peptides corresponding to either 39-154 or 39-267 aa residues bind specifically with human sperm (Baibakov et al., 2012; Avella et al., 2016). Interestingly, human ZP2 peptide (39-154 aa residues) coated beads prevented the binding and penetration of the human sperm to the transgenic eggs expressing human ZP2 in place of mouse ZP2 (Avella et al., 2016; Figure 2). Using immobilized baculovirus-expressed recombinant human ZP2 in a solid-phase immunoassay, binding of capacitated human sperm has been reported with ZP2, though it was lower as compared to immobilized ZP4 and ZP3 (Chirinos et al., 2011).

On the other hand, binding studies with E. coli-expressed $\mathrm{N}$-terminal fragment of recombinant human ZP2 (39-242 aa residues, excluding signal peptide) revealed that it does not bind to the capacitated acrosome-intact human spermatozoa but showed binding to $\sim 63 \%$ of acrosome-reacted spermatozoa. The binding sites are observed in the region from the acrosome to the midpiece (Tsubamoto et al., 1999; Table 1). These 


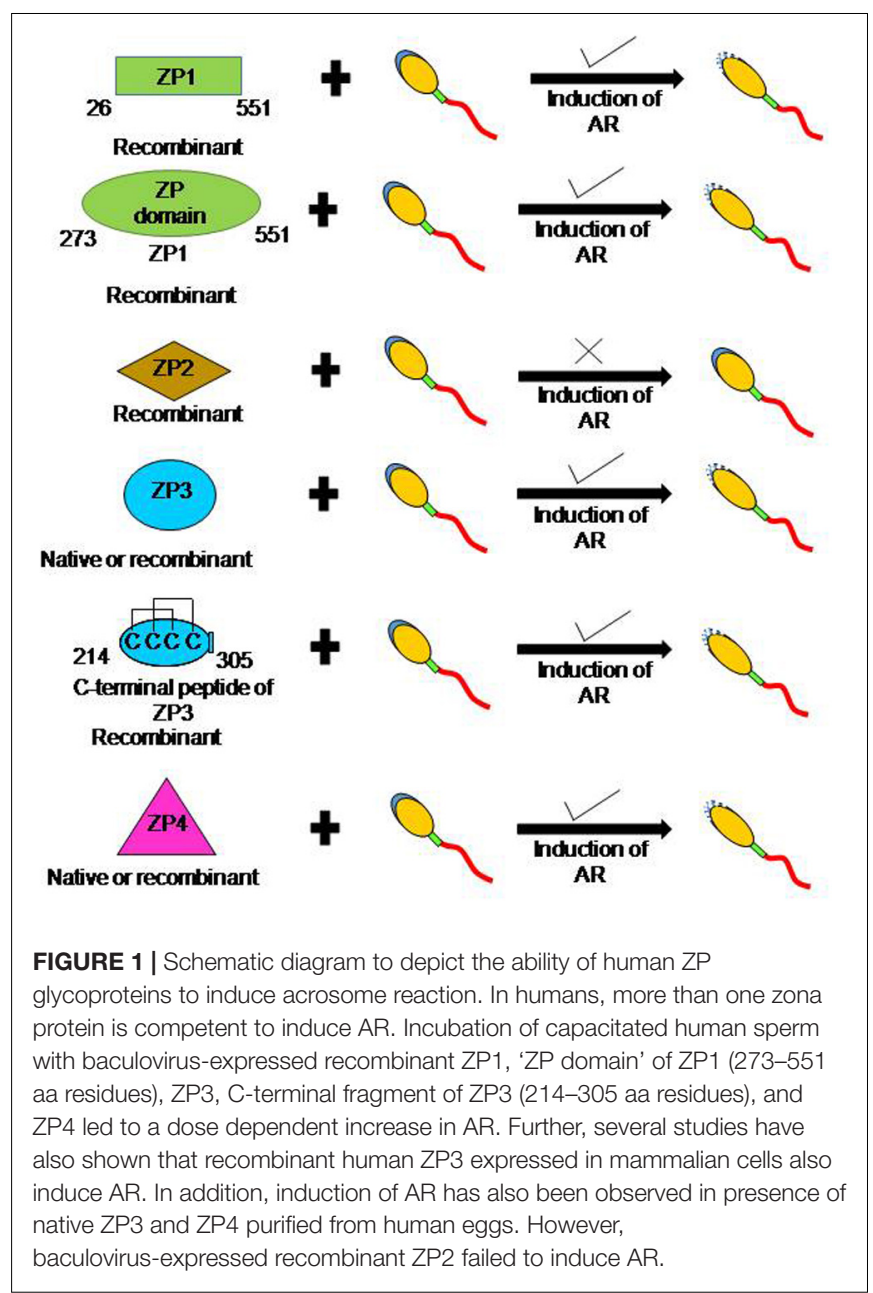

observations are further confirmed by employing E. coli (38645 aa)-/baculovirus (1-745 aa)-expressed recombinant human $\mathrm{ZP} 2$, wherein binding is observed only to the equatorial region of the acrosome-reacted human sperm (Chakravarty et al., 2008; Table 1). The native ZP2 purified from human eggs using immunoaffinity column binds over the equatorial region, postacrosomal region and midpiece of the capacitated acrosomeintact human spermatozoa. In acrosome-reacted human sperm, ZP2 showed binding to the acrosome region as well as in the post-acrosome region, equatorial region and midpiece (Chiu et al., 2008b; Table 1). Incubation of capacitated human sperm with baculovirus-expressed recombinant human ZP2 does not lead to any significant increase in the AR as compared to spontaneous AR (Chakravarty et al., 2005; Figure 1). The role of human ZP2 as observed using either transgenic mice or purified native/recombinant proteins in human sperm-egg binding is summarized in Table 2.

\section{Human ZP3}

Transgenic Mice Studies Revealed That ZP3 Has No Role in Sperm-Oocyte Binding

To understand the role of ZP3 in sperm-egg binding and fertilization, using gene-targeting and embryonic stem cell technologies ZP3 null mouse cell lines have been developed. The ZP3 null mice have follicles with germinal vesicle intact oocytes but completely lack a ZP matrix and have a disorganized corona radiata (Liu et al., 1996; Rankin et al., 1996). The females of these mice are sterile and the developmental potential of their oocytes is highly compromised. Subsequently, using transgenesis mouse lines have been developed wherein mouse ZP3 has been replaced with human ZP3 thereby expressing human-mouse chimeric ZP (human ZP3, mouse ZP1, and mouse $\mathrm{ZP2}$ ). As compared to ZP3 null mouse, it led to the restoration of ZP matrix (Rankin et al., 2003). The eggs with mosaic ZP (mouse ZP1, mouse ZP2, and human ZP3) failed to bind human sperm. However, the mouse sperm bind to these eggs and these transgenic mice are fertile (Rankin et al., 1998). In another additional study, it has been shown that human sperm fail to bind to the transgenic zonae expressing human ZP3 in place of mouse ZP3 (Baibakov et al., 2012). These studies using transgenic mice suggested that ZP3 is not involved in human sperm-egg binding.

\section{Native/Recombinant Human ZP3 Binds to Capacitated Human Spermatozoa and Induces AR}

To study the role of human ZP3 in sperm-oocyte binding and induction of $\mathrm{AR}$, it has been expressed using both prokaryotic as well as eukaryotic expression systems (van Duin et al., 1994; Dong et al., 2001; Bray et al., 2002; Chakravarty et al., 2005; Caballero-Campo et al., 2006; Jose et al., 2010; Chirinos et al., 2011). Recombinant human ZP3 expressed in human ovarian teratocarcinoma (PA-1) cells showed dose-dependent inhibition of in vitro sperm-ZP binding in a hemizona assay (Dong et al., 2001). Baculovirus-expressed recombinant human ZP3 (1-424 aa residues) labeled with FITC binds to either acrosomal cap or equatorial region of the capacitated acrosome-intact sperm whereas its binding is restricted to the equatorial region only in the acrosome-reacted human sperm (Chakravarty et al., 2008; Table 1). E. coliexpressed recombinant human ZP3 (23-348 aa residues) also showed similar binding profile with spermatozoa (Table 1). Native human ZP3 $(\sim 58 \mathrm{kDa})$ purified from human eggs also binds to the acrosomal region, equatorial region and midpiece of the capacitated acrosome-intact spermatozoa. However, binding of native ZP3 was restricted to midpiece of the acrosome-reacted spermatozoa (Chiu et al., 2008b; Table 1).

By and large, E. coli-expressed recombinant human ZP3 (devoid of glycosylation) failed to induce AR when incubated with capacitated human sperm (Chakravarty et al., 2005, 2008). However, ZP3 expressed using either baculovirus expression system or mammalian expression system leads to a dose and time dependent increase in AR. Studies by various investigators have shown that approximately $10-28 \%$ capacitated human sperm undergo AR (AR in presence of ZP3 minus spontaneous AR) when treated with recombinant ZP3 (van Duin et al., 1994; Dong et al., 2001; Bray et al., 2002; Chakravarty et al., 2005, 2008; Figure 1). These observations have been further consolidated by showing that the native human ZP3 purified from human eggs also induces dose 
TABLE 2 | Salient findings on the role of human ZP glycoproteins in sperm-egg binding and induction of AR using either transgenic animal models or native/recombinant proteins.

\begin{tabular}{|c|c|c|}
\hline \multirow{2}{*}{$\begin{array}{l}\text { Human zona } \\
\text { pellucida protein }\end{array}$} & \multicolumn{2}{|l|}{ Functional aspect of human ZP glycoproteins by using } \\
\hline & Transgenic animals & Purified proteins \\
\hline ZP1 & $\begin{array}{l}\text { Eggs from transgenic mouse lines with zonae expressing human ZP1, } \\
\text { mouse ZP2, and mouse ZP3 failed to bind human sperm suggesting no } \\
\text { role for human ZP1 in sperm-egg binding }\end{array}$ & $\begin{array}{l}\text { Baculovirus-expressed recombinant human ZP1 binds } \\
\text { to the capacitated human spermatozoa and induce } \\
\text { dose-dependent AR }\end{array}$ \\
\hline ZP2 & $\begin{array}{l}\text { Eggs from transgenic mouse lines with zonae expressing human ZP2, } \\
\text { mouse ZP1, and mouse ZP3 as well as those expressing human ZP1-4 } \\
\text { in place of mouse ZP1-3 bind human sperm and sperm accumulated in } \\
\text { perivitelline space have undergone AR. The spermatozoa binding site } \\
\text { resides in the N-terminal fragment of ZP2. ZP2 plays an important role } \\
\text { in sperm-egg binding. }\end{array}$ & $\begin{array}{l}\text { Human sperm bind to beads coated with recombinant } \\
\text { human ZP2 peptide (39-154 aa residues). Other } \\
\text { studies using native/recombinant protein revealed ZP2 } \\
\text { binding to acrosome-reacted human spermatozoa and } \\
\text { its inability to induce AR in capacitated human sperm. }\end{array}$ \\
\hline ZP3 & $\begin{array}{l}\text { Eggs from transgenic mouse lines with zonae expressing human ZP3, } \\
\text { mouse ZP1, and mouse ZP2 do not bind human sperm suggesting that } \\
\text { ZP3 has no role in sperm-egg binding. }\end{array}$ & $\begin{array}{l}\text { Native/recombinant ZP3 binds to the capacitated } \\
\text { human spermatozoa and numerous studies showed } \\
\text { that it induces AR in capacitated human spermatozoa. }\end{array}$ \\
\hline ZP4 & $\begin{array}{l}\text { Eggs from transgenic mouse lines with zonae expressing human ZP4, } \\
\text { mouse ZP1-3 failed to bind human sperm suggesting no role for human } \\
\text { ZP4 in taxon-specific sperm-egg binding }\end{array}$ & $\begin{array}{l}\text { Native/recombinant ZP4 binds to the capacitated } \\
\text { human spermatozoa and induce AR. }\end{array}$ \\
\hline
\end{tabular}

dependent increase in AR (Chiu et al., 2008a; Figure 1). In presence of native human ZP3 (25 pmol/ml), 37\% human sperm undergo AR as compared to $\sim 10 \%$ spontaneous $\mathrm{AR}$. The maximal AR was observed after $15 \mathrm{~min}$ of incubation with ZP3 (Chiu et al., 2008a). The ability of human ZP3 to bind to the capacitated human spermatozoa and induction of $\mathrm{AR}$ resides in its $\mathrm{C}$-terminal fragment corresponding to 214-305 aa residues (Bansal et al., 2009; Figure 1). However, in another study, E. coli-expressed recombinant human ZP3 peptides corresponding to 22-176 and 177-348 aa residues do induce AR that could be inhibited by pertussis toxin, EGTA and pimozide- a T-type calcium channel blocker (Ni et al., 2007).

Initial classical studies done in mouse model showed ZP3 as the zona ligand for sperm-egg binding and induction of AR (Bleil and Wassarman, 1983; Beebe et al., 1992). Molecular genetic approaches based on exon swapping and sitedirected mutagenesis revealed that the spermatozoa binding site of mouse ZP3 is encoded by exon 7 (Kinloch et al., 1995). Subsequently, O-glycans attached to $\operatorname{Ser}^{332}$ and $\operatorname{Ser}^{334}$ of ZP3 have been shown to be critical for its biological activity (Florman and Wassarman, 1985; Chen et al., 1998). However, mice deficient in glycosyl transferase were fertile suggesting that terminal galactose in alpha linkage is not critical for sperm-egg binding (Thall et al., 1995). Further studies showed that terminal galactose and $N$-acetylglucosamine of ZP3 are also not required for fertilization in mouse (Williams et al., 2007). O-linked glycosylation of $\mathrm{Ser}^{332}$ and $\mathrm{Ser}^{334}$ has not been observed in ZP3 purified from mouse eggs by mass spectrometry (Boja et al., 2003). Transgenic mouse lines with mutated serine residues of $\mathrm{ZP} 3$ have been developed (Liu et al., 1995). The eggs obtained from these transgenic mice showed normal sperm binding and mice were fertile when mated with normal male (Liu et al., 1995). Moreover, when ZP3 transgene with $\mathrm{Ser}^{332}$ to $\mathrm{Ala}^{332}$ and $\mathrm{Ser}^{334}$ to $\mathrm{Ala}^{334}$ mutations were introduced into $\mathrm{ZP} 3$ null mice, the resulting mice were fertile suggesting that sperm binding and AR took place in absence of normal mouse ZP3 (Gahlay et al., 2010).

\section{Human ZP4}

\section{Transgenic Animal Models Suggests No Role for Human ZP4 in Taxon-Specific Sperm-Egg Binding}

To investigate the role of ZP4 in taxon-specific sperm-egg binding, transgenic mouse lines have been developed that expressed human ZP4 in addition to the mouse ZP1, ZP2, and ZP3 in the ZP matrix of growing oocytes (Yauger et al., 2011). Mating studies of transgenic mice expressing human ZP4 with normal male mice resulted in litters with a size comparable with non-transgenic female mice. In vitro sperm binding assay revealed that only mouse sperm and not human sperm bind to the mouse eggs expressing human ZP4 (Yauger et al., 2011; Baibakov et al., 2012). The binding of mouse sperm to the transgenic mouse eggs is comparable to the non-transgenic mouse eggs. These studies suggested that ZP4 may not be sufficient for taxon-specific sperm binding to the egg (Yauger et al., 2011). Recently, the relevance of ZP4 in maintenance of appropriate ZP matrix and in vivo preimplantation development of the blastocyst has been shown in ZP4 knock out female rabbits. However, fertilization is not affected in the ZP4 knock out animals (Lamas-Toranzo et al., 2019). Thus, observations from transgenic mouse as well as rabbit model suggest that $\mathrm{ZP} 4$ may not have role in spermegg binding.

\section{Native/Recombinant Human ZP4 Binds to Human Spermatozoa and Induce AR}

The initial evidence that ZP4 may have a role in human 'sperm-oocyte' binding came by using recombinant human ZP4 (Chakravarty et al., 2008; Table 1). Interestingly, binding of both ZP3 and ZP4 to the same capacitated spermatozoon has been demonstrated by using triple staining, suggesting that these two proteins may have different binding sites on the 


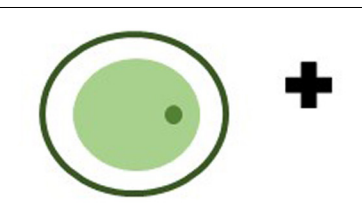

Mouse egg

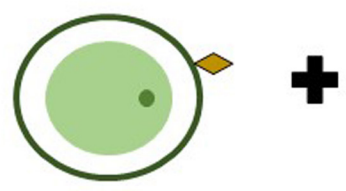

Mouse egg expressing human ZP2 along with mouse ZP1 and ZP3 or human ZP1-4 in place of mouse ZP1-3 or $\mathrm{N}$-terminal fragment of human ZP2 (22-164 aa residues)

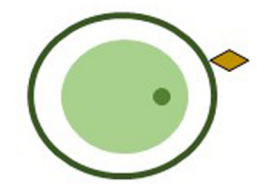

Mouse egg expressing human ZP2, mouse ZP1, and mouse ZP3

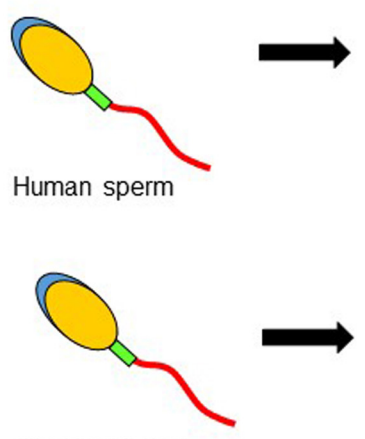

Human sperm
No binding

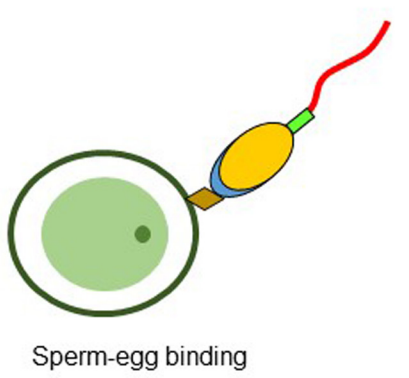

No binding

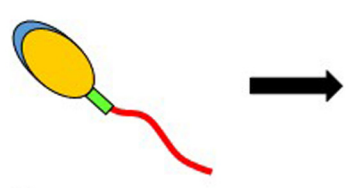

Human sperm

$+$

Beads coated with

human ZP2 peptide (39-154 aa)

FIGURE 2 | Schematic diagram to illustrate binding of human sperm to transgenic mouse oocyte expressing human ZP2. No binding of human capacitated sperm is observed when incubated with mouse eggs expressing mouse ZP1, ZP2, and ZP3. However, zonae from transgenic mouse lines expressing either human ZP2, mouse ZP1, and mouse ZP3 or human ZP1-4 in place of mouse ZP1-3 or those expressing human ZP2 N-terminal fragment corresponding to 22-164 aa residues instead of mouse ZP2, showed binding with human sperm suggesting its important role in human sperm-egg binding. Agarose beads coated with human ZP2 peptide (39-154 aa residues) inhibited the binding of human sperm to transgenic mouse oocytes expressing human ZP2 (Baibakov et al., 2012; Avella et al., 2014, 2016).

spermatozoon. Higher percentage of sperm showed binding of ZP4 to the acrosome region of the capacitated acrosomeintact sperm as compared to ZP3 (Chakravarty et al., 2008). In another independent study using immobilized baculovirusexpressed recombinant human ZP2, ZP3, and ZP4, highest number of sperm bound to ZP4 followed by ZP3 and ZP2 (Chirinos et al., 2011). Binding of native human ZP4 purified from human eggs to the entire head of the capacitated acrosomeintact human spermatozoa has also been demonstrated, which disappears after acrosome reaction (Chiu et al., 2008b; Table 1). Studies from the other species also suggest that ZP4 may have a role in sperm-egg binding. In rabbits, recombinant $\mathrm{ZP} 4$ binds to the acrosome of rabbit sperm (Prasad et al., 1996). Similarly, in porcine (Yurewicz et al., 1998) and bovine (Kanai et al., 2007) heterocomplexes of $\mathrm{ZP} 3$ and $\mathrm{ZP} 4$ are responsible for sperm-egg binding. The salient findings on the role of human ZP4 in spermegg binding as observed by using either transgenic animal models or native/recombinant protein are summarized in Table 2.

As the case with baculovirus-expressed human ZP1 and ZP3, incubation of capacitated human sperm with baculovirusexpressed human ZP4 also led to a dose dependent increase in AR (Chakravarty et al., 2005, 2008; Caballero-Campo et al., 2006; Figure 1). Dose dependent studies with baculovirus-expressed recombinant human $\mathrm{ZP} 4$ revealed that as low as $1 \mu \mathrm{g} / \mathrm{ml}$ protein induced a significant increase in AR. The significant increase in $\mathrm{AR}$ is observed after $15 \mathrm{~min}$ treatment with the recombinant protein, which plateau at $60 \mathrm{~min}$. Approximately $22 \%$ sperm undergo $\mathrm{AR}$ in presence of recombinant $\mathrm{ZP} 4$ $(20 \mu \mathrm{g} / \mathrm{ml})$ as compared to $\sim 9 \%$ spontaneous $\mathrm{AR}$ under similar experimental conditions (Chakravarty et al., 2005). Further, incubation of capacitated sperm with purified native human ZP4 also led to a dose-dependent increase in AR (Chiu et al., 2008a; Figure 1). Approximately 29\% capacitated human sperm undergo AR when treated with native human ZP4 $(25 \mathrm{pmol} / \mathrm{ml})$ as compared to $\sim 10 \%$ spontaneous AR. Interestingly, simultaneous treatment of capacitated human sperm with native ZP3 and ZP4 lead to an increase in the percentage of sperm undergoing AR to about 38\% (Chiu et al., 2008a). Two monoclonal antibodies (MA-1662, MA-1671) generated against human ZP4 significantly inhibited baculovirusexpressed recombinant ZP4-mediated AR. Using recombinant peptides expressed in E. coli, the minimal epitope of MA-1671 was mapped to 126-130 aa residues and MA-1662 was mapped to 256-260 aa residues. These observations suggest that both $N$ - and $C$-terminal parts of human ZP4 may be relevant for induction of AR (Xu et al., 2012). 


\section{ROLE OF ZP GLYCANS IN HUMAN OOCYTE-SPERM BINDING AND INDUCTION OF ACROSOMAL EXOCYTOSIS}

\section{Oocyte-Sperm Binding}

Both glycans as well as protein-protein interactions have been shown to play a role during human oocyte-sperm binding. The observations that $E$. coli-expressed recombinant human $\mathrm{ZP1}, \mathrm{ZP} 3$, and ZP4 bind to the capacitated acrosome-intact sperm support the hypothesis that protein-protein interaction is sufficient for binding of the $\mathrm{ZP}$ proteins to the spermatozoa (Chakravarty et al., 2008; Ganguly et al., 2010b). Homozygous mutant mice expressing $N$-terminal mouse ZP2 sperm binding domain with $N$-glycan site mutated $\left(\mathrm{mo} Z P 2^{N 83 Q}\right)$ in a $Z P 2^{N u l l}$ background showed normal mouse sperm binding to the oocytes suggesting that gamete recognition is glycan-independent (Tokuhiro and Dean, 2018). In the context of human spermegg binding, confirmation of these findings is still awaited from this group using gene-edited mice expressing human ZP2 N-terminal fragment with appropriate mutations in the glycosylation site(s).

On the contrary, mannose (which is present on human ZP glycoproteins) can inhibit in vitro human fertilization (Mori et al., 1989). Several oligosaccharides along with complex glycoconjugates bearing selectin-like ligands have been shown to be involved in human sperm-egg binding (Oehninger et al., 1998). In a hemizona binding assay, decrease in human sperm binding to human hemizona has been reported when sperm were pre-incubated with GlcNAc, mannose, fucose and galactose (Miranda et al., 1997). Periodate oxidation of human $\mathrm{ZP}$ suggested that sialic acid is also involved in human sperm-egg binding (Ozgur et al., 1998). Further, the sialylLewis $^{x}$ present on $\mathrm{N}$ - and $\mathrm{O}$-linked glycans of human ZP plays an important role in human sperm-oocyte binding as pre-incubation of human sperm with it or its conjugate with bovine serum albumin or antibodies against it leads to inhibition of human sperm-oocyte binding (Pang et al., 2011). In another independent study, it has been shown that human ZP matrix is coated with high density of complex type $N$-glycans terminated with the sialyl-Lewis ${ }^{x}$ sequence. In hemizona assay, sialyl-Lewis ${ }^{x}$ tetrasaccharide as well as neoglycoproteins terminated by sialyl-Lewis ${ }^{x}$ showed significant inhibition of human sperm-ZP binding (Clark, 2013). By using chemoenzymatically synthesized highly complex triantennary $N$-glycans again confirmed that sialyl-Lewis ${ }^{x}$ moiety is critical for human sperm-egg binding (Chinoy et al., 2018). On the other hand, eggs obtained from transgenic mice expressing human ZP2, mouse ZP1, and mouse ZP3 that bind human sperm do not show expression of sialyl-Lewis ${ }^{x}$ expression suggesting that it may not be critical for sperm-egg binding (Avella et al., 2014).

\section{Acrosome Reaction}

As discussed in Section "Role of Human ZP Glycoproteins in Binding to the Spermatozoa and Induction of Acrosome
Reaction," E. coli-expressed recombinant ZP1, ZP3, and ZP4 by and large failed to induce AR in the capacitated human spermatozoa in spite of their binding to spermatozoa (Chakravarty et al., 2005, 2008; Ganguly et al., 2010b). Baculovirus-expressed recombinant human ZP3 and ZP4 deficient in $N$-linked glycosylation showed significant reduction in their ability to induce AR, whereas removal of $O$-linked glycosylation (by alkali treatment) has no adverse effect on their ability to induce AR (Chakravarty et al., 2008). Further, removal of $N$-linked glycosylation by $N$-glycosidase-F from native ZP3 and ZP4 purified from human eggs also significantly inhibited their ability to induce $A R$ in capacitated human sperm as compared to untreated ZP3 and ZP4. As in case of baculovirus expressed recombinant proteins, removal of O-linked glycosylation of purified native ZP3 and ZP4 does not significantly decrease AR (Chiu et al., 2008a). These observations suggest that $N$-linked glycans of human zona proteins are more relevant than $O$-linked glycans for their ability to induce AR.

\section{CONCLUDING COMMENTS}

Using eggs from transgenic mouse lines expressing human ZP1, $\mathrm{ZP} 2, \mathrm{ZP} 3$, and $\mathrm{ZP} 4$, it has been demonstrated that $\mathrm{ZP} 2$ plays an important role in human sperm-egg binding whereas $Z P 1$, $\mathrm{ZP}$, and ZP4 may not be relevant for sperm-egg binding. On the contrary, using purified native and/or recombinant proteins, it has been shown that human ZP1, ZP3, and ZP4 binds to the capacitated human spermatozoa and induce AR. There may be various probable reasons for failure of human sperm to bind to the mouse transgenic zonae expressing human $\mathrm{ZP1}, \mathrm{ZP}$, and $\mathrm{ZP} 4$. One of the possibilities is that mouse $\mathrm{ZP}$ matrix $(\sim 8 \mu \mathrm{m})$ is thinner than human $\mathrm{ZP}$ matrix $(12 \mu \mathrm{m})$. It is possible that the stoichiometry of human $\mathrm{ZP} 1, \mathrm{ZP} 3$, and ZP4 incorporated in the transgenic mouse zonae may be different as compared to human zonae. Further, the epitopes/domains of the human zona proteins responsible for human sperm binding may not be accessible in the transgenic mouse zonae. Though based on mobility on SDS-PAGE, human proteins expressed in transgenic mice zonae are post-translationally modified to a similar extent as observed in native human zona proteins, but the possibility of differential glycosylation of human zona proteins in the transgenic mouse remains. If glycosylation plays an important role in human sperm-egg binding, it may be a critical factor and needs to be investigated. Further, contribution, if any from oligosacharides of ZP glycoproteins in imparting species specificity of 'sperm-oocyte' binding also needs investigations. It may be imperative to complement the non-binding of human sperm to mouse transgenic zonae expressing human ZP1, ZP3, and ZP4 with positive results showing human sperm binding by improving assay conditions for sperm-egg binding to support that transgenic mouse model physiologically mimics human gamete recognition. On the other hand, use of individual native/recombinant human zona proteins to study their binding characteristics with spermatozoa and/or induction of AR has a limitation that physiologically, spermatozoa binds to the $\mathrm{ZP}$ matrix that has all the four glycoproteins present in $\mathrm{ZP}$ matrix. 
Further, analyses of mutations in the gene encoding human zona proteins from infertile women suggest that ZP1, ZP2, and ZP3 have a role in fertility and assembly of ZP matrix.

\section{AUTHOR CONTRIBUTIONS}

SG studied and critically analyzed the information available and wrote this review.

\section{REFERENCES}

Avella, M. A., Baibakov, B., and Dean, J. (2014). A single domain of the ZP2 zona pellucida protein mediates gamete recognition in mice and humans. J. Cell Biol. 205, 801-809. doi: 10.1083/jcb.201404025

Avella, M. A., Baibakov, B. A., Jimenez-Movilla, M., Sadusky, A. B., and Dean, J. (2016). ZP2 peptide beads select human sperm in vitro, decoy mouse sperm in vivo, and promote reversible contraception. Sci. Transl. Med. 8:336ra60. doi: $10.1126 /$ scitranslmed.aad 9946

Avella, M. A., Xiong, B., and Dean, J. (2013). The molecular basis of gamete recognition in mice and humans. Mol. Hum. Reprod. 19, 279-289. doi: 10.1093/ molehr/gat004

Baibakov, B., Boggs, N. A., Yauger, B., Baibakov, G., and Dean, J. (2012). Human sperm bind to the N-terminal domain of ZP2 in humanized zonae pellucidae in transgenic mice. J. Cell Biol. 197, 897-905. doi: 10.1083/jcb.201203062

Bansal, P., Chakrabarti, K., and Gupta, S. K. (2009). Functional activity of human ZP3 primary sperm receptor resides toward its C-terminus. Biol. Reprod. 81, 7-15. doi: 10.1095/biolreprod.108.074716

Bauskin, A. R., Franken, D. R., Eberspaecher, U., and Donner, P. (1999). Characterization of human zona pellucida glycoproteins. Mol. Hum. Reprod. 5, 534-540. doi: 10.1093/molehr/5.6.534

Bedford, J. M. (1977). Sperm/egg interaction: the specificity of human spermatozoa. Anat. Rec. 188, 477-488. doi: 10.1002/ar.1091880407

Beebe, S. J., Leyton, L., Burks, D., Ishikawa, M., Fuerst, T., Dean, J., et al. (1992). Recombinant mouse ZP3 inhibits sperm binding and induces the acrosome reaction. Dev. Biol. 151, 48-54. doi: 10.1016/0012-1606(92)90212-y

Bercegeay, S., Jean, M., Lucas, H., and Barriere, P. (1995). Composition of human zona pellucida as revealed by SDS-PAGE after silver staining. Mol. Reprod. Dev. 41, 355-359. doi: 10.1002/mrd.1080410311

Bleil, J. D., and Wassarman, P. M. (1983). Sperm-egg interactions in the mouse: sequence of events and induction of the acrosome reaction by zona pellucida glycoprotein. Dev. Biol. 95, 317-324. doi: 10.1016/0012-1606(83)90032-5

Boja, E. S., Hoodbhoy, T., Fales, H. M., and Dean, J. (2003). Structural characterization of native mouse zona pellucida proteins using mass spectrometry. J. Biol. Chem. 278, 34189-34202. doi: 10.1074/jbc.M304026200

Bokhove, M., and Jovine, L. (2018). Structure of zona pellucida module proteins. Curr. Top. Dev. Biol. 130, 413-442. doi: 10.1016/bs.ctdb.2018.02.007

Bork, P., and Sander, C. (1992). A large domain common to sperm receptors (Zp2 and Zp3) and TGF-beta type III receptor. FEBS Lett. 300, 237-240. doi: 10.1016/0014-5793(92)80853-9

Bray, C., Son, J. H., Kumar, P., Harris, J. D., and Meizel, S. (2002). A role for the human sperm glycine receptor/ $/ \mathrm{Cl}^{-}$channel in the acrosome reaction initiated by recombinant ZP3. Biol. Reprod. 66, 91-97. doi: 10.1095/biolreprod66.1.91

Bukovsky, A., Gupta, S. K., Bansal, P., Chakravarty, S., Chaudhary, M., Svetlikova, M., et al. (2008). Production of monoclonal antibodies against recombinant human zona pellucida glycoproteins: utility in immunolocalization of respective zona proteins in ovarian follicles. J. Reprod. Immunol. 78, 102-114. doi: 10.1016/j.jri.2007.10.004

Burkart, A. D., Xiong, B., Baibakov, B., Jimenez-Movilla, M., and Dean, J. (2012). Ovastacin, a cortical granule protease, cleaves ZP2 in the zona pellucida to prevent polyspermy. J. Cell Biol. 197, 37-44. doi: 10.1083/jcb.201112094

Caballero-Campo, P., Chirinos, M., Fan, X. J., González-González, M. E., GaliciaChavarria, M., Larrea, F., et al. (2006). Biological effects of recombinant human zona pellucida proteins on sperm function. Biol. Reprod. 74, 760-768. doi: 10.1095/biolreprod.105.047522

\section{FUNDING}

Financial support from National Institute of Immunology, New Delhi, India, J. C. Bose National Fellowship (SB/S2/JCB040/2015) by Science and Engineering Research Board, Department of Science and Technology, Government of India and Department of Biotechnology (BT/ADV/Canine Health/TANUVAS/2017-18), Government of India is gratefully acknowledged.

Canosa, S., Adriaenssens, T., Coucke, W., Dalmasso, P., Revelli, A., Benedetto, C., et al. (2017). Zona pellucida gene mRNA expression in human oocytes is related to oocyte maturity, zona inner layer retardance and fertilization competence. Mol. Hum. Reprod. 23, 292-303. doi: 10.1093/molehr/gax008

Chakravarty, S., Kadunganattil, S., Bansal, P., Sharma, R. K., and Gupta, S. K. (2008). Relevance of glycosylation of human zona pellucida glycoproteins for their binding to capacitated human spermatozoa and subsequent induction of acrosomal exocytosis. Mol. Reprod. Dev. 75, 75-88. doi: 10.1002/mrd. 20726

Chakravarty, S., Suraj, K., and Gupta, S. K. (2005). Baculovirus-expressed recombinant human zona pellucida glycoprotein-B induces acrosomal exocytosis in capacitated spermatozoa in addition to zona pellucida glycoprotein-C. Mol. Hum. Reprod. 11, 365-372. doi: 10.1093/molehr/ gah165

Chen, J., Litscher, E. S., and Wassarman, P. M. (1998). Inactivation of the mouse sperm receptor, $\mathrm{mZP} 3$, by site-directed mutagenesis of individual serine residues located at the combining site for sperm. Proc. Natl. Acad. Sci. U.S.A. 95, 6193-6197. doi: 10.1073/pnas.95.11/6193

Chen, T., Bian, Y., Liu, X., Zhao, S., Wu, K., Yan, L., et al. (2017). A recurrent missense mutation in ZP3 causes empty follicle syndrome and female infertility. Am. J. Hum. Genet. 101, 459-465. doi: 10.1016/j.ajhg.2017.08.001

Chinoy, Z. S., Friscourt, F., Capicciotti, C. J., Chiu, P., and Boons, G.-J. (2018). Chemoenzymatic synthesis of asymmetrical multi-antennary $\mathrm{N}$-glycans to dissect glycan-mediated interactions between human sperm and oocytes. Chemistry 24, 7970-7975. doi: 10.1002/chem.201800451

Chirinos, M., Cariňo, C., González-González, M. E., Arreola, E., Reveles, R., and Larrea, F. (2011). Characterization of human sperm binding to homologous recombinant zona pellucida proteins. Reprod. Sci. 18, 876-885. doi: 10.1177/ 1933719111398146

Chiu, P. C., Wong, B. S., Chung, M. K., Lam, K. K., Pang, R. T., Lee, K. F., et al. (2008a). Effects of native human zona pellucida glycoproteins-3 and -4 on acrosome reaction and zona pellucida binding of human spermatozoa. Biol. Reprod. 79, 869-877. doi: 10.1095/biolreprod.108.069344

Chiu, P. C., Wong, B. S., Lee, C. L., Pang, R. T., Lee, K. F., Sumitro, S. B., et al. (2008b). Native human zona pellucida glycoproteins: purification and binding properties. Hum. Reprod. 23, 1385-1393. doi: 10.1093/humrep/ den 047

Clark, G. F. (2013). The role of carbohydrate recognition during human sperm-egg binding. Hum. Reprod. 28, 566-577. doi: 10.1093/humrep/des447

Dai, C., Hu, L., Gong, F., Tan, Y., Cai, S., Zhang, S., et al. (2019). ZP2 pathogenic variants cause in vitro fertilization failure and female infertility. Genet. Med. 21, 431-440. doi: 10.1038/s41436-018-0064-y

Dong, K. W., Chi, T. F., Juan, Y. W., Chen, C. W., Lin, Z., Xiang, X. Q., et al. (2001). Characterization of the biologic activities of a recombinant human zona pellucida protein 3 expressed in human ovarian teratocarcinoma (PA-1) cells. Am. J. Obstet. Gynecol. 184, 835-844. doi: 10.1067/mob.2001.113849

Familiari, G., Nottola, S. A., Macchiarelli, G., Micara, G., Aragona, C., and Motta, P. M. (1992). Human zona pellucida during in vitro fertilization: an ultrastructural study using saponin, ruthenium red, and osmium-thiocarbohydrazide. Mol. Reprod. Dev. 32, 51-61. doi: 10.1002/mrd.1080320109

Familiari, G., Nottola, S. A., Micara, G., Aragona, C., and Motta, P. M. (1988). Is the sperm-binding capability of the zona pellucida linked to its surface structure? A scanning electron microscopic study of human in vitro fertilization. J. Vitro Fert. Embryo Transf. 5, 134-143. doi: 10.1007/BFO1131175 
Familiari, G., Relucenti, M., Heyn, R., Micara, G., and Correr, S. (2006). Threedimensional structure of the zona pellucida at ovulation. Microsc. Res. Tech. 69, 415-426. doi: 10.1002/jemt.20301

Florman, H. M., and Wassarman, P. M. (1985). O-linked oligosaccharides of mouse egg ZP3 accounts for its sperm receptor activity. Cell 41, 313-324. doi: 10.1016/0092.8674(85)90084-4

Gahlay, G., Gauthier, L., Baibakov, B., Epifano, O., and Dean, J. (2010). Gamete recognition in mice depends on the cleavage status of an egg's zona pellucida protein. Science 329, 216-219. doi: 10.1126/science.1188178

Ganguly, A., Bansal, P., Gupta, T., and Gupta, S. K. (2010a). 'ZP domain' of human zona pellucida glycoprotein-1 binds to human spermatozoa and induces acrosomal exocytosis. Reprod. Biol. Endocrinol. 8:110. doi: 10.1186/1477-78278- 110

Ganguly, A., Bukovsky, A., Sharma, R. K., Bansal, P., Bhandari, B., and Gupta, S. K. (2010b). In humans, zona pellucida glycoprotein-1 binds to spermatozoa and induces acrosomal exocytosis. Hum. Reprod. 25, 1643-1656. doi: 10.1093/ humrep/dcq105

Gook, D. A., Edgar, D. H., Borg, J., and Martic, M. (2008). Detection of zona pellucida proteins during human folliculogenesis. Hum. Reprod. 23, 394-402. doi: 10.1093/humrep/dem373

Goudet, G., Mugnier, S., Callebaut, I., and Monget, P. (2008). Phylogenetic analysis and identification of pseudogenes reveal a progressive loss of zona pellucida genes during evolution of vertebrates. Biol. Reprod. 78, 796-806. doi: 10.1095/ biolreprod.107.064568

Green, D. P. (1997). Three-dimensional structure of the zona pellucida. Rev. Reprod. 2, 147-156. doi: 10.1530/ror.0.0020147

Greve, J. M., and Wassarman, P. M. (1985). Mouse egg extracellular coat is a matrix of interconnected filaments possessing a structural repeat. J. Mol. Biol. 181, 253-264. doi: 10.1016/0022-2836(85)90089-0

Gupta, S. K. (2018). The human egg's zona pellucida. Curr. Top. Dev. Biol. 130, 379-411. doi: 10.1016/bs.ctdb.2018.01.001

Gupta, S. K., Bhandari, B., Shrestha, A., Biswal, B. K., Palaniappan, C., Malhotra, S. S., et al. (2012). Mammalian zona pellucida glycoproteins: structure and function during fertilization. Cell Tissue Res. 349, 665-678. doi: 10.1007/s00441011-1319-y

Gupta, S. K., Yurewicz, E. C., Sacco, A. G., Kaul, R., Jethanandani, P., and Govind, C. K. (1998). Human zona pellucida glycoproteins: characterization using antibodies against recombinant non human primate ZP1, ZP2 and ZP3. Mol. Hum. Reprod. 4, 1058-1064. doi: 10.1093/molehr/4.11.1058

Hartmann, J. F., Gwatkin, R. B., and Hutchison, C. F. (1972). Early contact interactions between mammalian gametes in vitro: evidence that the vitellus influences adherence between sperm and zona pellucida. Proc. Natl. Acad. Sci. U.S.A. $69,2767-2769$.

Huang, H. L., Lv, C., Zhao, Y. C., Li, W., He, X. M., Li, P., et al. (2014). Mutant ZP1 in familial infertility. N. Eng. J. Med. 370, 1220-1226.

Hughes, D. C., and Barrat, C. L. (1999). Identification of the true human orthologue of the mouse $\mathrm{Zp} 1$ gene: evidence for greater complexity in the mammalian zona pellucida? Biochim. Biophys. Acta 1447, 303-306. doi: 10.1016/s0167-4781(99) 00181-5

Jiménez-Movilla, M., Avilés, M., Gómez-Torres, M. J., Fernández-Colom, P. J., Castells, M. T., de Juan, J., et al. (2004). Carbohydrate analysis of the zona pellucida and cortical granules of human oocytes by means of ultrastructural cytochemistry. Hum. Reprod. 19, 1842-1855. doi: 10.1093/humrep/deh311

Jimenez-Movilla, M., and Dean, J. (2011). ZP2 and ZP3 cytoplasmic tails prevent premature interactions and ensure incorporation into the zona pellucida. J. Cell Sci. 124, 940-950. doi: 10.1242/jcs.079988

Jose, O., Hernandez-Hernandez, O., Chirinos, M., González-González, M. E., Larrea, F., Almanza, A., et al. (2010). Recombinant human ZP3-induced sperm acrosome reaction: evidence for the involvement of T- and L-type voltagegated calcium channels. Biochem. Biophys. Res. Commun. 395, 530-534. doi: 10.1016/j.bbrc.2010.04.059

Jovine, L., Darie, C. C., Litscher, E. S., and Wassarman, P. M. (2005). Zona pellucida domain proteins. Annu. Rev. Biochem. 74, 83-114. doi: 10.1146/ annurev.biochem.74.082803.133039

Jovine, L., Qi, H., Williams, Z., Litscher, E. S., and Wassarman, P. M. (2002). The $\mathrm{ZP}$ domain is a conserved module for polymerization of extracellular proteins. Nat. Cell Biol. 4, 457-461. doi: 10.1038/ncb802
Kanai, S., Yonezawa, N., Ishii, Y., Tanokura, M., and Nakano, M. (2007). Recombinant bovine zona pellucida glycoproteins ZP3 and ZP4 co-expressed in Sf9 cells form a sperm-binding active hetero-complex. FEBS J. 274, 5390-5405. doi: $10.1111 / j .1742-4658.2007 .06065 . x$

Kiefer, S. M., and Saling, P. (2002). Proteolytic processing of human zona pellucida proteins. Biol. Reprod. 66, 407-414. doi: 10.1095/biolreprod66.2.407

Kinloch, R. A., Sakai, Y., and Wassarman, P. M. (1995). Mapping the mouse ZP3 combining site for sperm by exon swapping and site-directed mutagenesis. Proc. Natl. Acad. Sci. U.S.A. 92, 263-267. doi: 10.1073/pnas.92.1.263

Kipersztok, S., Osawa, G. A., Liang, L. F., Modi, W. S., and Dean, J. (1995). POMZP3, a bipartite transcript derived from human ZP3 and a POM121 homologue. Genomics 25, 354-359. doi: 10.1016/0888-7543(95)80033-i

Lamas-Toranzo, I., Balvis, N. F., Querejeta-Fernandez, A., Izquierdo-Rico, J. M., Gonzalez-Brusi, L., Lorenzo, P. L., et al. (2019). ZP4 confers structural properties to the zona pellucida essential for embryo development. eLife 8:e48904. doi: 10.7554/eLife.48904

Lefievre, L., Conner, S. J., Salpekar, A., Olufowobi, O., Ashton, P., Pavlovic, B., et al. (2004). Four zona pellucida glycoproteins are expressed in the human. Hum. Reprod. 19, 1580-1586. doi: 10.1093/humrep/deh301

Liu, C., Litcher, E. S., Mortillo, S., Kinloch, R. A., Stewart, C. L., and Wassarman, P. M. (1996). Targeted disruption of the $\mathrm{mZp} 3$ gene results in production of eggs lacking zona pellucida and infertility in female mice. Proc. Natl. Acad. Sci. U.S.A. 93, 5431-5436. doi: 10.1073/pnas.93.11.5431

Liu, C., Litcher, E. S., and Wassarman, P. M. (1995). Transgenic mice with reduced numbers of functional sperm receptors on their eggs reproduce normally. Mol. Biol. Cell. 6, 577-585. doi: 10.109/mbc.6.5.577

Liu, W., Li, K., Bai, D., Yin, J., Tang, Y., Chi, F., et al. (2017). Dosage effects of ZP2 and ZP3 heterozygous mutations cause human infertility. Hum. Genet. 136, 975-985. doi: 10.1007/s00439-017-1822-7

Louros, N. N., Chrysina, E. D., Baltatzis, G. E., Patsouris, E. S., Hamodrakas, S. J., and Iconomidou, V. A. (2016). A common 'aggregation-prone' interface possibly participates in the self-assembly of human zona pellucida proteins. FEBS Lett. 590, 619-630. doi: 10.1002/1873-3468.12099

Louros, N. N., Iconomidou, V. A., Giannelou, P., and Hamodrakas, S. J. (2013). Structural analysis of peptide-analogues of human zona pellucida ZP1 protein with amyloidogenic properties: insights into mammalian zona pellucida formation. PLoS One 8:e73258. doi: 10.1371/journal.pone.0073258

Magerkurth, C., Töpfer-Peterson, E., Schwartz, P., and Michelmann, H. W. (1999). Scanning electron microscopy analysis of the human zona pellucida: influence of maturity and fertilization on morphology and sperm binding pattern. Hum. Reprod. 14, 1057-1066. doi: 10.1093/humrep/14.4.1057

Männikkö, M., Törmälä, R.-M., Tuuri, T., Haltia, A., Martikainen, H., Ala-Kokko, L., et al. (2005). Association between sequence variations in genes encoding human zona pellucida glycoproteins and fertilization failure in IVF. Hum. Reprod. 20, 1578-1585. doi: 10.1093/humrep/deh837

Maymon, B. B., Maymon, R., Ben-Nun, I., Ghetler, Y., Shalgi, R., and Skutelsky, E. (1994). Distribution of carbohydrates in the zona pellucida of human oocytes. J. Reprod. Fertil. 102, 81-86. doi: 10.1530/jrf.0.1020081

Miranda, P. V., Gonzalez-Echeverria, F., Marin-Briggiler, C. I., Brandelli, A., Blaquier, J. A., and Tezon, J. G. (1997). Glycosidic residues involved in human sperm-zona pellucida binding in vitro. Mol. Hum. Reprod. 3, 399-404. doi: 10.1093/molehr/3.5.399

Mori, K., Daitoh, T., Irahara, M., Kamada, M., and Aono, T. (1989). Significance of D-mannose as a sperm receptor site on the zona pellucida in human fertilization. Am. J. Obstet. Gynecol. 161, 207-211. doi: 10.1016/0002-9378(89) 90267-6

Ni, Y., Li, K., Xu, W., Song, L., Yao, K., Zhang, X., et al. (2007). Acrosome reaction induced by recombinant human zona pellucida 3 peptides rhuZP2a 22 approximately 176 and rhuZP3b 177 approximately 348 and their mechanism. J. Androl. 28, 381-388. doi: 10.2164/jandrol.106.001289

Nishimura, K., Dioguardi, E., Nishio, S., Villa, A., Han, L., Matsuda, T., et al. (2019). Molecular basis of egg coat cross-linking sheds light on ZP1-associated female infertility. Nat. Commun. 10:3086. doi: 10.1038/s41467-019-10 931-5

Oehninger, S., Patankar, M., Seppala, M., and Clark, G. F. (1998). Involvement of selectin-like carbohydrate binding specificity in human gamete interaction. Andrologia 30, 269-274. doi: 10.1111/j.1439-0272.1998.tb01170.x 
Ozgur, K., Patankar, M. S., Oehninger, S., and Clark, G. F. (1998). Direct evidence for the involvement of carbohydrate sequences in human sperm-zona pellucida binding. Mol. Hum. Reprod. 4, 318-324. doi: 10.1093/molehr/4.4.318

Pang, P. C., Chiu, P. C., Lee, C. L., Chang, L. Y., Panico, M., Morris, H. R., et al. (2011). Human sperm binding is mediated by the sialyl-Lewis(x) oligosaccharide on the zona pellucida. Science 333, 1761-1764. doi: 10.1126/ science. 1207438

Pökkylä, R. M., Lakkakorpi, J. T., Nuojua-Huttunen, S. H., and Tapanainen, J. S. (2011). Sequence variations in human $\mathrm{ZP}$ genes as potential modifiers of zona pellucida architecture. Fertil. Steril. 95, 2669-2672. doi: 10.1016/j.fertnstert. 2011.01.168

Prasad, S. V., Wilkins, B., Skinner, S. M., and Dunbar, B. S. (1996). Evaluating zonapellucida structure and function using antibodies to rabbit $55 \mathrm{kDa} Z \mathrm{ZP}$ protein expressed in baculovirus expression system. Mol. Reprod. Dev. 43, 519-529.

Rankin, T., Famillari, M., Lee, E., Ginsberg, A., Dwyer, N., Blanchette-Mackie, J., et al. (1996). Mice homozygous for an insertional mutation in the Zp3 gene lack a zona pellucida and are fertile. Development 122, 2903-2910.

Rankin, T., Talbot, P., Lee, E., and Dean, J. (1999). Abnormal zonae pellucidae in mice lacking ZP1 result in early embryonic loss. Development 126, 3847-3855.

Rankin, T. L., Coleman, J. S., Epifano, O., Hoodbhoy, T., Turner, S. G., Castle, P. E., et al. (2003). Fertility and taxon-specific sperm binding persist after replacement of mouse 'sperm receptors' with human homologues. Dev. Cell. 5 , 33-43. doi: 10.1016/s1534-5807(03)00195-3

Rankin, T. L., O’Brien, M., Lee, E., Wigglesworth, K. E., and Dean, J. (2001). Defective zonae pellucidae in $\mathrm{Zp} 2$ null mice disrupt folliculogenesis, fertility and development. Development 128, 1119-1126.

Rankin, T. L., Tong, Z. B., Castle, P. E., Lee, E., Gore-Langton, R., Nelson, L. M., et al. (1998). Human ZP3 restores fertility in Zp3 null mice without affecting order-specific sperm binding. Development 125, 2415-2424.

Shabanowitz, R. B., and O'Rand, M. G. (1988). Characterization of the human zona pellucida from fertilized and unfertilized eggs. J. Reprod. Fertil. 82, 151-161. doi: 10.1530/jrf.0.0820151

Sun, L., Fang, X., Chen, Z., Zhang, H., Zhang, Z., Zhou, P., et al. (2019). Compound heterozygous ZP1 mutations cause empty follicle syndrome in infertile sisters. Hum. Mutat. 40, 2001-2006. doi: 10.1002/humu.23864

Thall, A. D., Maly, P., and Lowe, J. B. (1995). Oocyte Gal alpha 1,3Gal epitopes implicated in sperm adhesion to the zona pellucida glycoprotein ZP3 are not required for fertilization of mouse. J. Biol. Chem. 270, 21437-21440. doi: 10. 1074/jbc.270.37.21437

Thim, L. (1989). A new family of growth factor-like peptides. 'Trefoil' disulphide loop structures as a common feature in breast cancer associated peptide (pS2), pancreatic spasmolytic polypeptide (PSP), and frog skin peptides (spasmolysins). FEBS Lett. 250, 85-90. doi: 10.1016/0014-5793(89)80690-8

Tokuhiro, K., and Dean, J. (2018). Glycan-independent gamete recognition triggers egg zinc sparks and ZP2 cleavage to prevent polyspermy. Dev. Cell. 46, 627640.e5. doi: 10.1016/j.devcel.2018.07.020

Törmälä, R.-M., Jääskeläinen, M., Lakkakorpi, J., Liakka, A., Tapanainen, J. S., and Vaskivuo, T. E. (2008). Zona pellucida components are present in human fetal ovary before follicle formation. Mol. Cell. Endocrinol. 289, 10-15. doi: 10.1016/j.mce.2008.01.029

Tsubamoto, H., Hasegawa, A., Nakata, Y., Naito, S., Yamasaki, N., and Koyama, K. (1999). Expression of recombinant human zona pellucida protein 2 and its binding capacity to spermatozoa. Biol. Reprod. 61, 1649-1654. doi: 10.1095/ biolreprod61.6.1649

van Duin, M., Polman, J. E., de Breet, I. T., van Ginneken, K., Bunschoten, H., Grootenhuis, A., et al. (1994). Recombinant human zona pellucida protein ZP3 produced by Chinese hamster ovary cells induces the human sperm acrosome reaction and promotes sperm-egg fusion. Biol. Reprod. 51, 607-617. doi: 10. 1095/biolreprod51.4.607

van Duin, M., Polman, J. E., Verkoelen, C. C., Bunschoten, H., Meyerink, J. H., Olijve, W., et al. (1992). Cloning and characterization of the human sperm receptor ligand $\mathrm{ZP} 3$ : evidence for a second polymorphic allele with a different frequency in the Caucasian and Japanese populations. Genomics 14, 1064-1070. doi: 10.1016/s0888-7543(05)80130-2

Williams, S. A., Xia, L., Cummings, R. D., McEver, R. P., and Stanley, P. (2007). Fertilization in the mouse does not require terminal galactose or $\mathrm{N}$-acetylglucosamine on the zona pellucida glycans. J. Cell. Sci. 120, 1341-1349. doi: 10.1242/jcs.004291

Xu, W. X., Bhandari, B., He, Y. P., Tang, H. P., Chaudhary, S., Talwar, P., et al. (2012). Mapping of epitopes relevant for induction of acrosome reaction on human zona pellucida glycoprotein-4 using monoclonal antibodies. Am. J. Reprod. Immunol. 68, 465-475. doi: 10.1111/j.1600-0897.2012.01177.x

Yang, P., Luan, X., Peng, Y., Chen, T., Su, S., Zhang, C., et al. (2017). Novel zona pellucida gene variants identified in patients with oocyte anomalies. Fertil. Steril. 107, 1364-1369. doi: 10.1016/j.fertnstert.2017.03.029

Yauger, B., Boggs, N. A., and Dean, J. (2011). Human ZP4 is not sufficient for taxon-specific sperm recognition of the zona pellucida in transgenic mice. Reproduction 141, 313-319.

Yurewicz, E. C., Sacco, A. G., Gupta, S. K., Xu, N., and Gage, D. A. (1998). Heterooligomerization-dependent binding of pig oocyte zona pellucida glycoproteins ZPB and ZPC to boar sperm membrane vesicles. J. Biol. Chem. 273, 7488-7494. doi: 10.1074/jbc.273.13.7488

Zhou, Z., Ni, C., Wu, L., Chen, B., Xu, Y., Zhang, Z., et al. (2019). Novel mutations in $\mathrm{ZP} 1, \mathrm{ZP} 2$, and ZP3 cause female infertility due to abnormal zona pellucida formation. Hum. Genet. 138, 327-337. doi: 10.1007/s00439-019-01990-1

Conflict of Interest: The author declares that the research was conducted in the absence of any commercial or financial relationships that could be construed as a potential conflict of interest.

Copyright (c) 2021 Gupta. This is an open-access article distributed under the terms of the Creative Commons Attribution License (CC BY). The use, distribution or reproduction in other forums is permitted, provided the original author(s) and the copyright owner(s) are credited and that the original publication in this journal is cited, in accordance with accepted academic practice. No use, distribution or reproduction is permitted which does not comply with these terms. 